\title{
Secondary Prevention of Cervical Cancer: ASCO Resource-Stratified Clinical Practice Guideline
}

\section{Citation}

Jeronimo, J., P. E. Castle, S. Temin, L. Denny, V. Gupta, J. J. Kim, S. Luciani, et al. 2016. "Secondary Prevention of Cervical Cancer: ASCO Resource-Stratified Clinical Practice Guideline." Journal of Global Oncology 3 (5): 635-657. doi:10.1200/JG0.2016.006577. http:// dx.doi.org/10.1200/JG0.2016.006577.

\section{Published Version}

doi:10.1200/JG0.2016.006577

\section{Permanent link}

http://nrs.harvard.edu/urn-3:HUL.InstRepos:34493231

\section{Terms of Use}

This article was downloaded from Harvard University's DASH repository, and is made available under the terms and conditions applicable to Other Posted Material, as set forth at http:// nrs.harvard.edu/urn-3:HUL.InstRepos:dash.current.terms-of-use\#LAA

\section{Share Your Story}

The Harvard community has made this article openly available.

Please share how this access benefits you. Submit a story.

\section{Accessibility}




\section{Secondary Prevention of Cervical Cancer: ASCO Resource-Stratified Clinical Practice Guideline}

Jose Jeronimo

Philip E. Castle

Sarah Temin

Lynette Denny

Vandana Gupta

Jane J. Kim

Silvana Luciani

Daniel Murokora

Twalib Ngoma

Youlin Qiao

Michael Quinn

Rengaswamy

Sankaranarayanan

Peter Sasieni

Kathleen M. Schmeler

Surendra S. Shastri

Author affiliations and support information (if applicable) appear at the end of this article.

This guideline has been endorsed by the

International Gynecologic Cancer Society and the American Society for Colposcopy and Cervical Pathology (Data Supplement).

Clinical Practice Guideline Committee Approved: July 5, 2016

Reprint Requests: 2318 Mill Rd, Ste 800,

Alexandria, VA 22314; guidelines@asco.org Corresponding author: American Society of Clinical Oncology, 2318 Mill Rd, Ste 800 , Alexandria, VA 22314; e-mail: guidelines@ asco.org.

Purpose To provide resource-stratified, evidence-based recommendations on the secondary prevention of cervical cancer globally.

Methods ASCO convened a multidisciplinary, multinational panel of oncology, primary care, epidemiology, health economic, cancer control, public health, and patient advocacy experts to produce recommendations reflecting four resource-tiered settings. A review of existing guidelines, a formal consensus-based process, and a modified ADAPTE process to adapt existing guidelines were conducted. Other experts participated in formal consensus.

Results Seven existing guidelines were identified and reviewed, and adapted recommendations form the evidence base. Four systematic reviews plus cost-effectiveness analyses provided indirect evidence to inform consensus, which resulted in $\geq 75 \%$ agreement.

Recommendations Human papillomavirus (HPV) DNA testing is recommended in all resource settings; visual inspection with acetic acid may be used in basic settings. Recommended age ranges and frequencies by setting are as follows: maximal: ages 25 to 65 , every 5 years; enhanced: ages 30 to 65 , if two consecutive negative tests at 5 -year intervals, then every 10 years; limited: ages 30 to 49, every 10 years; and basic: ages 30 to 49, one to three times per lifetime. For basic settings, visual assessment is recommended as triage; in other settings, genotyping and/or cytology are recommended. For basic settings, treatment is recommended if abnormal triage results are present; in other settings, colposcopy is recommended for abnormal triage results. For basic settings, treatment options are cryotherapy or loop electrosurgical excision procedure; for other settings, loop electrosurgical excision procedure (or ablation) is recommended. Twelve-month post-treatment follow-up is recommended in all settings. Women who are HIV positive should be screened with HPV testing after diagnosis and screened twice as many times per lifetime as the general population. Screening is recommended at 6 weeks postpartum in basic settings; in other settings, screening is recommended at 6 months. In basic settings without mass screening, infrastructure for HPV testing, diagnosis, and treatment should be developed.

Additional information can be found at www.asco.org/rs-cervical-cancer-secondary-prev-guideline and www. asco.org/guidelineswiki.

It is the view of of ASCO that health care providers and health care system decision makers should be guided by the recommendations for the highest stratum of resources available. The guideline is intended to complement, but not replace, local guidelines.

\section{INTRODUCTION}

The purpose of this guideline is to provide expert guidance on secondary prevention with screening for cervical cancer to clinicians, public health authorities, policymakers, and laypersons in all resource settings. The target population is women in the general population at risk for developing cervical cancer (specific target ages depend on the resource level).

There are large disparities regionally and globally in incidence of and mortality resulting from cervical cancer, in part because of disparities in the provision of mass screening and primary prevention. Different regions of the world, both among and within countries, differ with respect to access to prevention and treatment.

Approximately $85 \%$ of incident cervical cancers occur in less developed regions (also known as lowand middle-income countries [LMICs]) around the world, representing $12 \%$ of women's cancers in those regions. Eighty-seven percent of deaths resulting from cervical cancer occur in these less-developed regions. ${ }^{1}$ Some of the regions in the world with the highest mortality rates include the WHO Southeast Asia and Western Pacific regions, followed by India and Africa. ${ }^{1}$ As a result of these disparities, the ASCO Resource-Stratified Guidelines Advisory Group 
THE BOTTOM LINE

\section{Secondary Prevention of Cervical Cancer: ASCO Resource-Stratified Clinical Practice Guideline}

\section{Guideline Question}

What are the optimal method(s) for cervical cancer screening and the management of women with abnormal screening results for each resource level (ie, basic, limited, enhanced, maximal)?

\section{Target Population}

Women who are asymptomatic for cervical cancer precursors or invasive cervical cancer

\section{Target Audience}

Public health authorities, cancer control professionals, policymakers, obstetricians/gynecologists, primary care providers, lay public

\section{Methods}

A multinational, multidisciplinary Expert Panel was convened to develop clinical practice guideline recommendations on the basis of a systematic review of existing guidelines and/or an expert consensus process.

Authors" note: It is the view of ASCO that health care providers and health care system decision makers should be guided by the recommendations for the highest stratum of resources available. The guidelines are intended to complement, but not replace, local guidelines.

\section{Key Recommendations}

\section{Primary Screening}

- Human papillomavirus (HPV) DNA testing is recommended in all resource settings.

- Visual inspection with acetic acid may be used in basic settings.

- The recommended age ranges and frequencies in each setting are as follows:

- Maximal: 25-65 years, every 5 years

- Enhanced: 30-65 years, if two consecutive negative tests at 5-years intervals, then every 10 years

- Limited: 30-49 years, every 10 years

- Basic: 30-49 years, one to three times per lifetime

\section{Exiting Screening}

- Maximal and enhanced: $\geqslant 65$ years with consistently negative results during past $\geqslant 15$ years

- Limited and basic: $\leqslant 49$ years, resource-dependent; see specific recommendations

\section{Triage}

- In basic settings, visual assessment for treatment may be used after positive HPV DNA testing results.

- If visual inspection with acetic acid was used as primary screening with abnormal results, women should receive treatment.

- For other settings, HPV genotyping and/or cytology may be used.

\section{After Triage}

- Women with negative triage results should receive follow-up in 12 months.

- In basic settings, women should be treated if there are abnormal or positive triage results. 
- In limited settings, women with abnormal results from triage should receive col poscopy, if available, or visual assessment for treatment, if colposcopy is not available.

- In maximal and enhanced settings, women with abnormal or positive results from triage should receive colposcopy.

\section{Treatment of Women With Precursor Lesions}

- In basic settings, treatment options are cryotherapy or loop electrosurgical excision procedure (LEEP).

- In other settings, LEEP (if high level of quality assurance) or ablation (if medical contraindication to LEEP) is recommended.

- Twelve-month post-treatment follow-up is recommended for all settings.

\section{Special Populations}

- Women who are HIV positive or immunosuppressed for other reasons should be screened with HPV as soon as diagnosed and screened twice as many times in a lifetime as the general population.

- The management of abnormal screening results for women with HIV and positive results of triage is the same as in the general population

- Women should be offered primary screening 6 weeks postpartum in basic settings and 6 months postpartum in other settings.

- Screening may be discontinued in women who have received a total hysterectomy for benign causes with no history of cervical dysplasia or HPV. Women who have received a subtotal hysterectomy (with an intact cervix) should continue receiving routine screening.

\section{Qualifying Statement}

In basic settings without current mass screening, infrastructure for HPV testing, diagnosis, and treatment should be developed.

\section{Additional Resources}

More information, including a Data Supplement, a Methodology Supplement with information about evidence quality and strength of recommendations, slide sets, and clinical tools and resources, is available at www.asco.org/rs-cervical-cancer-secondary-prev-guideline and www.asco.org/guidelineswiki. Patient information is available at www.cancer.net.

ASCO believes that cancer and cancer prevention clinical trials are vital to inform medical decisions and improve cancer care and that all patients should have the opportunity to participate.

chose cervical cancer as a priority topic for guideline development.

The primary goal of cervical cancer screening should be - and the emphasis of these guidelines is - the accurate detection and timely treatment of intraepithelial precursor lesions of the cervix at a population level for the purpose of cervical cancer prevention, rather than cancer control as for many other cancers. This is because these precursor lesions are readily found and diagnosable and are easily and effectively treated through outpatient services with minimal adverse events or sequelae. Earlier detection of cervical cancer at a lesser stage is also a benefit of screening, resulting in reduced morbidity and mortality. However, many low-resource settings have little capacity in terms of surgery and radiotherapy to treat women with invasive cervical cancer. ${ }^{2}$ Therefore, the ASCO Expert Panel that developed this guideline (Appendix Table A1) emphasizes the timely detection and treatment of cervical precancerous lesions before they become invasive. To achieve this, a high screening coverage and an organized screening program are necessary.

Human papillomavirus (HPV) causes virtually all cervical cancer and its immediate precursors everywhere in the world. High-quality screening programs can lower the incidence of cervical cancer by up to $80 \%{ }^{3}$ In the past three decades, mass 
screening in high-resource settings has achieved these reductions in cervical cancer incidence. ${ }^{4} \mathrm{~A}$ cervical cancer prevention program will affect the incidence and mortality rates only if women with positive screening results complete proper evaluation and treatment to prevent the progression to invasive cancer. Therefore, one of the critical evaluation indicators for any population-based program is the rate of completion of management and treatment in women who require it, which should ideally be $100 \%$.

In 2013 and 2014, WHO published guidelines on the screening and treatment of precursor lesions for women in all settings; this guideline reinforces those recommendations. The screening modalities addressed by WHO and this guideline, include cytology (also known as Papanicolaou, or Pap, test), visual inspection (eg, visual inspection with acetic acid [VIA]), and HPV DNA testing (screening). For evaluation of positive results, the $\mathrm{WHO}$ guidelines include colposcopy, and for treatment, the guidelines recommend loop electrosurgical excision procedure (LEEP) of the transformation zone and ablative treatments. The screening tests are sometimes used and have been studied alone and in combination. This ASCO guideline also addresses screening in the vaccination era, selfsampling, and emerging screening technologies.

In some settings that have established mass screening, cytology is the primary screening mode; in other settings, providers add HPV DNA testing (cotesting). Some countries and regions are moving toward or have adopted primary HPV DNA testing or VIA. 5,6

In low-resource settings, where screening may not currently be available, there is usually a shortage of pathologists, laboratories, colposcopists and other health providers, which limits the establishment of a traditional screening program. For example, some countries in sub-Saharan Africa have no pathologists $^{7,8}$ and/or laboratories. ${ }^{9}$ However, HPV DNA testing, which is more effective than the traditional cytology screening test, may be introduced without pathology and laboratories. Therefore, less infrastructure is needed compared with cytology testing $^{10}$ (see Cost and Policy Implications).

As HPV vaccination becomes more widespread and the rate of HPV infection decreases, public health authorities must decide on screening policies. Although prophylactic HPV vaccination may be the ultimate cervical cancer prevention strategy, current HPV vaccines prevent infections but do not treat pre-existing infections and conditions. ${ }^{11,12}$ Moreover, bivalent and quadrivalent HPV vaccines provide only partial protection against cervical cancer. Therefore, even if universal female
HPV vaccination could be rapidly deployed, there would still be several generations of at-risk, HPV-infected women who would not benefit from-and would unlikely be targeted for-HPV vaccination. Without robust screening, millions of women will die of cervical cancer before the impact of HPV vaccines on cervical cancer is observed. ${ }^{3}$ Thus, secondary prevention by cervical cancer screening will be needed for the foreseeable future. (See Special Commentary on vaccination and screening for an in-depth discussion.)

The diagnosis of cervical cancer precursors is based on the pathologist's judgment of the thickness of the transformed epithelium in biopsied or excised tissue, which is graded (in order of increasing severity) as negative or as cervical intraepithelial neoplasia (CIN) grade 1 ( $\mathrm{CIN1}$; up to one-third thickness of epithelium), grade 2 (CIN2; up to two-thirds thickness), or grade 3 (CIN3; twothirds thickness or greater). Other abnormal results may include atypical squamous cells (ASC), ASC of undetermined significance (ASC-US), and adenocarcinoma in situ (AIS), the glandular equivalent of CIN3 and the precursor to adenocarcinoma. In this guideline, the term precursor lesions refers to CIN2 or greater ( $\geqslant$ CIN2), defined as a diagnosis of CIN2 (the standard-of-care threshold that triggers treatment), CIN3, or AIS. CIN1 is not considered a precursor lesion; most cases of CIN1 regress within 6 years. ${ }^{13} \mathrm{CIN} 2$ is considered an equivocal precancerous diagnosis; that is, some instances of CIN2 are CIN1 or HPV infection, ${ }^{14}$ and therefore, treatment of all CIN2 may represent overtreatment. $^{15}$

ASCO has established a process for resourcestratified guidelines, which includes mixed methods of guideline development, adaptation of the clinical practice guidelines of other organizations, and formal expert consensus. This article summarizes the results of that process and presents resource-stratified recommendations that are based, in part, on formal consensus and adaptation from existing guidelines on the screening, triage of screening results, and treatment of women with cervical cancer precursor lesions (these guidelines are listed in Results and Appendix Table A2).

ASCO uses an evidence-based approach to inform guideline recommendations. In developing resource-stratified guidelines, ASCO has adopted its framework from the four-tier approach (basic, limited, enhanced, maximal; Table 1) developed by the Breast Health Global Initiative and made modifications to that framework on the basis of 
Table 1. Four-Tiered Resource Settings for Secondary Prevention

\begin{tabular}{|c|c|}
\hline Setting & Definition \\
\hline Basic & $\begin{array}{l}\text { Core resources or fundamental services absolutely necessary for any public health/ } \\
\text { primary health care system to function; basic-level services typically are applied in } \\
\text { a single clinical interaction; screening is feasible for highest need populations. }\end{array}$ \\
\hline Limited & $\begin{array}{l}\text { Second-tier resources or services that produce major improvements in outcomes, such as } \\
\text { incidence and cost effectiveness, but that are attainable with limited financial means } \\
\text { and modest infrastructure; limited-level services may involve single or multiple } \\
\text { interactions; universal public health interventions are feasible for a greater percentage } \\
\text { of the population than primary target group. }\end{array}$ \\
\hline Enhanced & $\begin{array}{l}\text { Third-tier resources or services that are optional but important; enhanced-level resources } \\
\text { may produce further improvements in outcome but increase the number and quality of } \\
\text { screening/treatment options and individual choice (perhaps ability to track patients and } \\
\text { links to registries). }\end{array}$ \\
\hline Maximal & $\begin{array}{l}\text { May use high-resource setting guidelines; high-level/state-of-the art resources or services } \\
\text { that may be used in some high-resource countries and/or may be recommended by } \\
\text { high-resource setting guidelines that do not adapt to resource constraints; this should } \\
\text { be considered lower priority than in the other settings on the basis of cost impracticality } \\
\text { for limited-resource environment. }\end{array}$ \\
\hline
\end{tabular}

NOTE. Data adapted. ${ }^{16,17}$

the Disease Control Priorities 3. ${ }^{16,17}$ Separate ASCO resource-stratified guidelines provide guidance on the treatment of women with invasive cervical cancer ${ }^{2}$ and on primary prevention (forthcoming).

\section{GUIDELINE QUESTIONS}

This clinical practice guideline addresses the following four overarching clinical questions: (1) What is the best method(s) for screening for each resource stratum? (2) What is the best triage strategy for women with positive results or other abnormal (eg, discordant HPV/cytology) results? (3) What are the best management strategies for women with precursors of cervical cancer? (4) What screening strategy should be recommended for women who have received HPV vaccination?

\section{METHODS}

These recommendations were developed by an ASCO Expert Panel with multinational and multidisciplinary representation (Appendix Table A1). The Expert Panel met via teleconference and in person and corresponded through e-mail. On the basis of the consideration of the evidence, the authors were asked to contribute to the development of the guideline, provide critical review, and finalize the guideline recommendations. Members of the Expert Panel were responsible for reviewing and approving the penultimate version of the guideline, which was then circulated for external review and submitted to a peer-reviewed journal for editorial review and consideration for publication. This guideline was partially informed by ASCO's modified
Delphi Formal Expert Consensus methodology, during which the Expert Panel was supplemented by additional experts recruited to rate their agreement with the drafted recommendations. The entire membership of experts is referred to as the Consensus Panel (Data Supplement provides a list of members). All ASCO guidelines are ultimately reviewed and approved by the Expert Panel and the ASCO Clinical Practice Guideline Committee before publication.

The guideline development process was also informed by the ADAPTE methodology as an alternative to de novo recommendation development. Adaptation of guidelines is considered by ASCO in selected circumstances, when one or more quality guidelines from other organizations already exist on the same topic. The objective of the ADAPTE process is to take advantage of existing guidelines to enhance efficient production, reduce duplication, and promote the local uptake of quality guideline recommendations.

The ASCO adaptation and formal expert consensus processes begin with a literature search to identify literature including candidate guidelines for adaptation. The panel used literature searches (from 1966 to 2015, with additional searches for literature published in specific areas), existing guidelines and expert consensus publications, some literature suggested by panel members, and clinical experience as guides.

Adapted guideline manuscripts are reviewed and approved by the Clinical Practice Guideline Committee. The review includes the following two parts: methodologic review and content review. The 
former was completed by two ASCO staff members and the latter by members of the Expert Panel convened by ASCO.

The guideline recommendations were crafted, in part, using the Guidelines Into Decision Support methodology and accompanying BRIDGE-Wiz software (Yale, New Haven, CT). ${ }^{19}$ Detailed information about the methods used to develop this guideline is available in the Data and Methodology Supplements at www.asco.org/rs-cervical-cancer-secondaryprev-guideline.

The ASCO Expert Panel and guidelines staff will work with the Steering Committee to keep abreast of any substantive updates to the guideline. On the basis of the formal review of the emerging literature, ASCO will determine the need to update this guideline.

This is the most recent information as of the publication date. Visit the ASCO Guidelines Wiki at (www.asco.org/guidelineswiki) to submit new evidence.

\section{Guideline Disclaimer}

The clinical practice guidelines and other guidance published herein are provided by ASCO to assist providers in clinical decision making. The information herein should not be relied upon as being complete or accurate, nor should it be considered as inclusive of all proper treatments or methods of care or as a statement of the standard of care. With the rapid development of scientific knowledge, new evidence may emerge between the time information is developed and when it is published or read. The information is not continually updated and may not reflect the most recent evidence. The information addresses only the topics specifically identified therein and is not applicable to other interventions, diseases, or stages of diseases. This information does not mandate any particular course of medical care. Furthermore, the information is not intended to substitute for the independent professional judgment of the treating provider, as the information does not account for individual variation among patients. Recommendations reflect high, moderate, or low confidence that the recommendation reflects the net effect of a given course of action. The use of words such as must, must not, should, and should not indicates that a course of action is recommended or not recommended for either most or many patients, but there is latitude for the treating physician to select other courses of action in individual cases. In all cases, the selected course of action should be considered by the treating provider in the context of treating the individual patient. Use of the information is voluntary. ASCO provides this information on an as-is basis and makes no warranty, express or implied, regarding the information. ASCO specifically disclaims any warranties of merchantability or fitness for a particular use or purpose. ASCO assumes no responsibility for any injury or damage to persons or property arising out of or related to any use of this information or for any errors or omissions.

\section{Guideline and Conflict of Interest}

The Expert Panel was assembled in accordance with ASCO's Conflict of Interest Policy Implementation for Clinical Practice Guidelines ("Policy," found at http://www.asco.org/rwc). All members of the Expert Panel completed ASCO's disclosure form, which requires disclosure of financial and other interests, including relationships with commercial entities that are reasonably likely to experience direct regulatory or commercial impact as a result of promulgation of the guideline. Categories for disclosure include employment; leadership; stock or other ownership; honoraria; consulting or advisory role; speaker's bureau; research funding; patents, royalties, other intellectual property; expert testimony; travel, accommodations, expenses; and other relationships. In accordance with the Policy, the majority of the members of the Expert Panel did not disclose any relationships constituting a conflict under the Policy.

\section{RESULTS}

\section{Literature Search}

As part of the systematic literature review, the PubMed, SAGE, Cochrane Systematic Review, and National Guideline Clearinghouse databases were searched for literature and guidelines, systematic reviews, and meta-analyses that were about screening for, or treatment of, precursor lesions; developed by multidisciplinary content experts as part of a recognized organizational effort; and published between 1966 and 2015.

Literature searches based on prespecified criteria as well as updates of literature searches with terms used by other guidelines were conducted, and a title screen was completed and abstract review begun. However, because several high- and moderatequality guidelines were found, the full text review and data extraction steps of the systematic review were not completed.

Searches for cost-effectiveness analyses (CEAs) were also conducted and titles, abstracts, and full 
texts were reviewed. Forty-one CEAs were found (this guideline cites three from these results, ${ }^{20-22}$ and panel members suggested an additional study ${ }^{23}$ ). Articles were excluded from the systematic review if they were meeting abstracts, books, editorials, commentaries, letters, news articles, case reports, or narrative reviews.

\section{Methods and Results of the ASCO Updated Literature Search}

A search for new evidence was conducted by ASCO guidelines staff to identify relevant randomized clinical trials, systematic reviews, meta-analyses, and guidelines published since the Cancer Care Ontario (CCO) and WHO guidelines were completed. Following the strategies described in the WHO guidelines, PubMed and EMBASE databases were searched from 2011 to December 2014 in July 2015. The search was restricted to articles published in English, and the ASCO guideline inclusion criteria were applied to review of the literature search results. Titles were reviewed; as described earlier, evidence reviews conducted for other societies' guidelines were used as the evidence base.

Sixteen guidelines were found in the search, and their currency, content, and methodology were reviewed. On the basis of content and methodology assessments, the Expert Panel chose seven guidelines as the evidentiary basis for the guideline recommendations; these guidelines were from the American Cancer Society (ACS)/American Society for Colposcopy and Cervical Pathology (ASCCP)/American Society for Clinical Pathology (ASCP) ${ }^{24,25}$; a second ASCCP-led effort ${ }^{26}$; another US-based multisociety group's guideline, referred to here as Huh et $\mathrm{al}^{6}$; $\mathrm{CCO}^{27}$; a European guideline, referred to as von Karsa et $\mathrm{al}^{5}$; and two guidelines from the WHO.28,29 (Note that at the time of this writing, the US Preventive Services Task Force was updating its guidelines. ${ }^{30}$ ) Appendix Table A2 contains links to these guidelines.

The existing guidelines cover different screening tests, including cytology, visual inspection, and HPV DNA testing; different modes of sampling cervical cells (clinician and self-sampling); different strategies when screening results are abnormal, also known as triage; the screen-andtreat strategy; the management of $\geqslant \mathrm{CIN} 2$; and the follow-up of women after receiving treatment of $\geqslant \mathrm{CIN} 2$, as well as secondary prevention for women in subpopulations, such as those with HIV.
This ASCO guideline reinforces selected recommendations offered in the ACS/ASCCP/ASCP, ASCCP, CCO, WHO, von Karsa et al, ${ }^{5}$ and Huh et $\mathrm{al}^{6}$ guidelines and acknowledges the effort put forth by the authors and aforementioned societies to produce evidence- and/or consensusbased guidelines informing practitioners and institutions.

These guidelines were published between 2011 and 2015. Six were based completely or in part on systematic reviews. ${ }^{5,24-29}$ The WHO guideline has the largest global constituency and makes recommendations for resource-constrained areas. All the other guidelines were developed in maximal resource-level settings. Various types and levels of evidence were used to support these guidelines. Randomized controlled trials (RCTs) have been conducted on the type of test for primary screening and the treatment of precursor lesions. For most of the other clinical questions, these guidelines were based on nonrandomized comparative studies, observational data, pooled analyses, modeling, and expert opinion. Appendix Table A2 lists links to and the Data Supplement provides an overview of the guidelines, including information on their clinical questions, target populations, development methodology, and details of key evidence.

\section{ASCO Methodologic Review}

The methodologic review of the guidelines was completed by two ASCO guideline staff members using the Rigor of Development subscale of the Appraisal of Guidelines for Research and Evaluation II instrument. ${ }^{31}$ The score for the Rigor of Development domain is calculated by summing the scores across individual items in the domain and standardizing the total score as a proportion of the maximum possible score. Detailed results of the scoring and the Appraisal of Guidelines for Research and Evaluation II assessment process for this guideline are available in the Methodology Supplement.

\section{FINAL RECOMMENDATIONS}

The recommendations were developed by a multinational, multidisciplinary group of experts using evidence from existing guidelines, supplementary literature, and clinical experience as guides. The ASCO Expert Panel underscores that public health officials and health care practitioners who implement the recommendations presented in this guideline should first identify the available resources in their local and referral facilities and endeavor to provide the highest level of care possible with those resources. 


\section{Maximal-Resource Setting}

In maximal-resource settings, cervical cancer screening with HPV DNA testing should be offered every 5 years from ages 25 to 65 years. On an individual basis, women may elect to receive screening until 70 years of age (Type: evidence based for test, interval, and age [25 to 65 years]; Type: formal consensus based [until age 70 years]; Evidence quality: high; Strength of recommendation: strong).

Women who are $\geqslant 65$ years of age who have had consistently negative screening results during the past $\geqslant 15$ years may cease screening. Women who are 65 years of age and have a positive result after age 60 should be reinvited to undergo screening 2, 5, and 10 years after the last positive result. If women have received no or irregular screening, they should undergo screening once at age 65 years, and if the result is negative, they should exit screening (Type: evidence based; Evidence quality: intermediate; Strength of recommendation: moderate).

If the results of the HPV DNA test are positive, clinicians should then perform triage with reflex genotyping for HPV 16/18 (with or without HPV 45) and/or cytology as soon as HPV test results are known (Type: evidence based; Evidence quality: high; Strength of recommendation: strong). If triage results are abnormal (ie, $\geqslant$ ASC-US or positive for HPV 16/18 [with or without HPV 45]), women should be referred to colposcopy, during which biopsies of any acetowhite (or suggestive of cancer) areas should be taken, even if the acetowhite lesion might appear insignificant. If triage results are negative (eg, primary HPV positive and cytology triage negative), then repeat HPV testing at the 12-month follow-up (Type: evidence based; Evidence quality: intermediate; Strength of recommendation: strong).

If HPV test results are positive at the repeat 12-month follow-up, refer women to colposcopy. If HPV test results are negative at the 12- and 24-month follow-ups or negative at any consecutive HPV test 12 months apart, then women should return to routine screening (Type: evidence based; Evidence quality: high; Strength of recommendation: strong).

Women who have received HPV and cytology cotesting triage and have HPV-positive results and abnormal cytology should be referred for colposcopy and biopsy. If results are HPV positive and cytology normal, repeat cotesting at 12 months. If at repeat testing HPV is still positive, patients should be referred for colposcopy and biopsy, regardless of cytology results (Type: formal consensus based; Evidence quality: intermediate; Strength of recommendation: strong).

If the results of the biopsy indicate that women have precursor lesions ( $\geqslant \mathrm{CIN} 2$ ), then clinicians should offer LEEP (if there is a high level of quality assurance $[Q A])^{32}$ or where LEEP is contraindicated, ablative treatments may be offered. (Type: evidence based; Evidence quality: high; Strength of recommendation: strong).

After women receive treatment of precursor lesions, follow-up should consist of HPV DNA testing at 12 months. If 12-month results are positive, continue annual screening; if not, return to routine screening (Type: formal consensus based; Evidence quality: intermediate; Strength of recommendation: moderate).

Source guidelines and discussion. The age range for HPV testing was modified from guidelines by Huh et $\mathrm{al}^{6}$ that based the age of initiation on the Addressing the Need for Advanced HPV Diagnostics (ATHENA) RCT used for US Food and Drug Administration registration. ${ }^{33}$ Adding the years 25 to 29 to the starting age recommended by CCO and $\mathrm{WHO}$ (30 years) is from the evidence that HPV testing benefits women who are HPV negative, including those age 25 to 29 years. ${ }^{6}$ Screening is not recommended for women under the age of 25 given the lack of evidence of the benefit of decreased cancer risk and the potential harms of screening and overtreatment. For example, as described in the Huh et al ${ }^{6}$ guideline, there is a lower 3-year cumulative incidence rate for women whose results were high-risk HPV type (hrHPV) negative. The age of cessation at 65 years is suggested on the basis of existing guidelines. In general, the criteria for exiting screening are determined primarily on resource availability and the average life span of women in each setting, which is matched with the current knowledge of the HPV infection-to-dysplasia process. As life expectancy in maximal resource settings (eg, Organization for Economic Cooperation and Development countries) increases, and where estimated incidence rates for women ages 60 to 64 and 65 to 69 years are similar (16.6 and 16.1 per 100,000 , respectively), ${ }^{1}$ women and their doctors may make individualized decisions to extend screening up to 70 years of age. For example, women who are 65 to 70 years old, have received screening, and have a history of positive screening (HPV, cytology, or VIA) test results in the last 5 years may be reinvited to screening until 70 years of age. 
The choice of HPV DNA testing is supported by evidence of its effectiveness as a screening test and by several existing guidelines from developers including WHO, von Karsa et al, ${ }^{5} \mathrm{Huh}$ et al, ${ }^{6}$ and CCO. HPV DNA testing is more sensitive than cytology. ${ }^{6}$ The interval of 5 years is based on the $\mathrm{WHO}, \mathrm{CCO}$, and European guidelines (CCO recommendations were specific to women older than age 30 years). There have been 10 RCTs on primary HPV testing. (The CCO guideline cites seven RCTs published between 2007 and 2010, including New Techniques in Cervical Cancer [NTCC], A Randomized Controlled Trial of HPV Testing in Primary Cervical Screening [ARTISTIC], PopulationBased Screening Study Amsterdam [POBASCAM], Swedescreen, Finnish Public Health Trial [FPHT], Sankaranarayanan et al, and Canadian Cervical Cancer Screening Trial [CCCaST]. ${ }^{27}$ ) The Huh etal ${ }^{6}$ guidance cites pooled analyses of European RCTs (Dillner et al, ${ }^{34}$ which included seven prospective studies, and Ronco etal, ${ }^{35}$ which included four of the trials in $\mathrm{CCO}$ that had data from two rounds of screening [ARTISTIC, POBASCAM, NTCC, and Swedescreen published between 2007 and 2012]), the Vrije Universiteit Medical Centre-Saltro (VUSA)-Screen study, ${ }^{36}$ the ATHENA RCT, and a Kaiser database. Ronco et $\mathrm{al}^{35}$ mentioned FOCAL, listed as ongoing by $\mathrm{CCO}$, which was not included in the Huh et al ${ }^{6}$ guidance. Selected RCT data have been extracted in the Data Supplement.

Cotesting is an option, as recommended by the ACS/ASCCP/ASC pathology guideline; however, the added value on the basis of increased costs is limited. Evidence for this statement is found in the Huh et $\mathrm{al}^{6}$ guideline and a 2014 publication including CEA from the ARTISTIC trial, which found that strategies using primary HPV screening were more cost-effective than those using cotesting (eg, the rate of primary HPV screening with cytology triage and repeat HPV at 12 or 24 months was $22 \%$ for vaccinated cohorts and $18 \%$ in unvaccinated cohorts). ${ }^{37,38}$

In maximal-resource settings, mass screening should be available to the entire target population and should aim to cover at least $80 \%$ of women age 25 to 70 years. Readers should note that there are more than 100 molecular tests for the detection of HPV; however, population-based screening programs should only use HPV tests that show clinical utility (which ASCO considers the highest level of evidence for biomarkers ${ }^{39}$ ), are properly validated, ${ }^{40,41}$ and are approved by national and/or international regulatory agencies, such as US Food and Drug Administration approval,
European Union CE marking, WHO endorsement/ prequalification, or other country- or regional-level regulatory agencies. The tests should also have confirmed good manufacturing practices.

Women who are 65 to 70 years of age and do not have a history of $\geqslant \mathrm{CIN} 3$ do not need to be offered screening if they have had two or more consecutive negative HPV test results or three or more negative cytology test results and only negative test results in the past 15 years.

If there are positive results from colposcopy, the options for the treatment of women with precursor lesions include LEEP, which is the first choice in maximal and enhanced settings, and various ablative treatments including cryotherapy, cold coagulation, or laser, which should all meet a high level of QA metrics (listed in Table 2). ${ }^{29,32}$ Cryotherapy is not recommended in the maximal setting. LEEP is preferred, in part, because it provides tissue for a histopathologic diagnosis. However, LEEP technology and training may not be available in lower resource settings and/or have contraindications. The Massad et $\mathrm{al}^{26}$ and $\mathrm{WHO}$ guidelines, citing RCTs and Cochrane reviews, and a more recent (2013) Cochrane review ${ }^{42}$ showed minimal differences between treatments. The WHO guideline states there is low evidence of treatment versus no treatment, mostly pooled results of noncomparative, nonrandomized studies. There are no RCTs specifically on HPV after LEEP. ${ }^{43}$ There is a paucity of prospective, comparative data on other treatment and follow-up strategies to guide recommendations on post-treatment follow-up. ${ }^{26}$ Therefore, on the basis of formal consensus, this guideline recommends follow-up HPV DNA testing at 12 months after one of these treatments.

\section{Enhanced-Resource Setting}

In enhanced-resource settings, cervical cancer screening with HPV DNA testing should be offered to women 30 to 65 years of age every 5 years (ie, second screen 5 years from the first; Type: evidence based; Evidence quality: high; Strength of recommendation: strong). If there are two consecutive negative screening test results, subsequent screening should be extended to every 10 years (Type: formal consensus based; Evidence quality: intermediate-low; Strength of recommendation: moderate).

Women who are $\geqslant 65$ years of age who have had consistently negative screening results during the past $\geqslant 15$ years may cease screening. Women who are 65 years of age and have a positive result after age 60 years should be reinvited to undergo 
Table 2. Quality Assurance Criteria for Treatment of Precursor Lesions

\begin{tabular}{|c|c|c|}
\hline Treatment Modality & Criteria & Source \\
\hline \multirow[t]{12}{*}{ LEEP } & $\begin{array}{l}\text { The results of VIA or VILI or colposcopy } \\
\text { positive, not suspicious for cancer unless } \\
\text { LEEP for biopsy and not treatment, can } \\
\text { identify full extent of external lesions, etc, } \\
>12 \text { weeks postpartum }\end{array}$ & Jhpiego $^{32}$ \\
\hline & $\begin{array}{l}\text { Sufficient training of provider, with ability to } \\
\text { handle complications }\end{array}$ & $\mathrm{WHO}^{4}$ \\
\hline & Absolute contraindications to LEEP & ASCO Expert Panel \\
\hline & Pregnancy & \\
\hline & Acute cervicitis & \\
\hline & Bleeding or coagulation disorders & \\
\hline & Patient unwillingness & \\
\hline & Relative contraindications to LEEP & \\
\hline & Patient $<3$ months postpartum & \\
\hline & $\begin{array}{l}\text { Recurrence in a postcervical conization } \\
\text { case }\end{array}$ & \\
\hline & Young patient with a small cervix & \\
\hline & Strong suspicion of microinvasive cancer & \\
\hline Ablation & $\begin{array}{l}\text { Lesion covers }<75 \% \text { of cervix, lesion does } \\
\text { not enter endocervical canal, patient does } \\
\text { not have positive ECC, entire lesion can be } \\
\text { visualized and covered by the cryotherapy } \\
\text { probe, no suspicion for invasive cancer }\end{array}$ & $\mathrm{WHO}^{29}$ \\
\hline
\end{tabular}

Abbreviations: ECC, endocervical curettage; LEEP, loop electrosurgical excision procedure; $\mathrm{VIA}$, visual inspection with acetic acid; VILI, visual inspection with Lugol's iodine.

screening 2, 5, and 10 years after the last positive result. If women have received no or irregular screening, they should undergo screening once at age 65 years, and if the result is negative, they should exit screening (Type: formal consensus based; Evidence quality: low; Strength of recommendation: weak).

If the results of the HPV DNA test are positive, clinicians should then perform triage with HPV genotyping for HPV 16/18 (with or without HPV 45) and/or reflex cytology (Type: evidence based; Evidence quality: high; Strength of recommendation: strong). If triage results are abnormal (ie, $\geqslant$ ASCUS or positive for HPV 16/18 [with or without HPV 45]), women should be referred to colposcopy, during which biopsies of any acetowhite (or suggestive of cancer) areas should be taken, even if the acetowhite lesion might appear insignificant. If triage results are negative (eg, primary HPV positive and cytology triage negative), then repeat HPV testing at the 12-month follow-up (Type: evidence based; Evidence quality: intermediate; Strength of recommendation: strong).

If HPV test results are positive at the repeat 12-month follow-up, refer women to colposcopy.
If HPV test results are negative at the 12- and 24-month follow-ups or negative at any consecutive HPV test 12 months apart, then women should return to routine screening (Type: evidence based; Evidence quality: high; Strength of recommendation: strong).

If the results of colposcopy and biopsy indicate that women have precursor lesions ( $\geqslant$ CIN2), then clinicians should offer LEEP (if there is a high level of QA) or, where LEEP is contraindicated, ablative treatments may be offered (Type: evidence based; Evidence quality: high; Strength of recommendation: strong). After women receive treatment of precursor lesions, follow-up should consist of HPV DNA testing at 12 months. If 12-month results are positive, continue annual screening; if not, return to routine screening (Type: formal consensus based; Evidence quality: intermediate; Strength of recommendation: moderate).

Source guidelines and discussion. In enhancedresource settings, which refer to most programs in urban areas of middle-income countries, public health authorities may narrow the screening age range to 30 to 65 years; this is in agreement with the CCO guidelines. There is insufficient evidence on the best age of cessation. ${ }^{44}$ The extension to 10 years after negative tests is based on the von Karsa et $\mathrm{al}^{5}$ guideline.

The cost analysis study by Beal et $\mathrm{al}^{21}$ (2014) was conducted from the perspective of Mexican health care institutions and compared the following four screening plus triage strategies: cytology alone, hrHPV with reflex cytology, hrHPV with molecular triage, and cotesting with molecular triage. The study found that when the base case was cytology alone, hrHPV with molecular triage had the lowest incremental cost-effectiveness ratio (ICER) (-819v-108.99v-537 for hrHPV with molecular triage, hrHPV with cytology triage, and cotesting, respectively), with a cost at US\$91.5 million (2013 US dollars). This strategy resulted in fewer women undergoing colposcopy. (Note that Mexico's 2013 gross national income per capita was $\$ 15,620$ [World Bank data, gross national income per capita, purchasing power parity]. ${ }^{45}$ )

As with the maximal-resource setting recommendations, if a woman has a history of positive screening (HPV, cytology, or VIA) test results in the past 5 years, she should be reinvited to screening. The interval may increase to 10 years in enhanced settings after two negative tests and is a modification of the von Karsa et $\mathrm{al}^{5}$ guidelines, which give the upper limit of 10 years after a negative test. This is also because HPV testing in older women yields a higher specificity. ${ }^{46}$ In the enhanced setting, if HPV 
genotyping is available, use this for triage. If HPV genotyping is not available, reflex cytology may be used, because the low predictive value of a positive HPV DNA test for finding $\geqslant$ CIN2 can be raised to the level of cytology by cytologic triage of HPV-positive women. ${ }^{47,48}$ Cytology for triage is recommended by the CCO and von Karsa et $\mathrm{al}^{5}$ guidelines.

Follow-up after triage is the same as in maximalresource settings. For management of precursor lesions, the Expert Panel recommends using LEEP as a first choice, but if LEEP is not available or is contraindicated and the patient is eligible for ablation (Table 2), ${ }^{29}$ then the clinician may use ablation. The other recommendations are the same as in the maximal setting.

\section{Limited-Resource Setting}

Cervical cancer screening with HPV DNA testing should be offered to women age 30 to 49 years every 10 years, corresponding to two to three times per lifetime (Type: evidence based [age range], Type: formal consensus based [interval]; Evidence quality: intermediate; Strength of recommendation: moderate).

If the results of the HPV DNA test are positive, clinicians should then perform triage with reflex cytology (quality assured) and/or HPV genotyping for HPV 16/18 (with or without HPV 45) or with visual assessment for treatment (VAT; for cytology and genotyping: Type: evidence based; Evidence quality: high; Strength of recommendation: strong; for VAT: Type: formal consensus based; Evidence quality: low; Strength of recommendation: weak).

If cytology triage results are abnormal (ie, $\geqslant$ ASCUS), women should be referred to quality-assured colposcopy (the first choice, if available and accessible), during which biopsies of any acetowhite (or suggestive of cancer) areas should be taken, even if the acetowhite lesion might appear insignificant. If colposcopy is not available, then perform VAT (Type: evidence based; Evidence quality: intermediate; Strength of recommendation: moderate).

If HPV genotyping or VAT triage results are positive, then women should be treated. If the results from both of these forms of triage are negative, then repeat HPV testing at the 12-month follow-up (Type: evidence based; Evidence quality: high; Strength of recommendation: strong). If test results are positive at the repeat 12-month follow-up, then women should be treated (Type: formal consensus based; Evidence quality: intermediate; Strength of recommendation: moderate).
For treatment, clinicians should offer ablation if the criteria are satisfied; if not and resources are available, then offer LEEP (if there is a high level of QA; Table 2; Type: evidence based; Evidence quality: high; Strength of recommendation: strong). After women receive treatment of precursor lesions, follow-up should consist of the same testing at 12 months (Type: formal consensus based; Evidence quality: intermediate; Strength of recommendation: moderate).

CEAs. The interval of 10 years (three times per lifetime) is supported by a CEA ${ }^{23}$ found in ASCO's literature search for CEAs and was based on data from demonstration projects in South Asia, Central America, and East Africa. The objective of this study was analyzing cost-effectiveness of various tests (HPV DNA test, VIA, and cytology), age ranges, screening intervals, and numbers of screens per lifetime in limited-resource settings. This analysis supported the WHO guidelines for the age range of 30 to 49 years and found that HPV DNA testing three times per lifetime every 10 years starting at age 30 was a cost-effective strategy with attractive ICERs of 350 to 580 (international dollars) per life-year saved (LYS), varying by region. Cost of screening three times per lifetime with intervals of 5 years ranged from $\$ 180$ to $\$ 1,600$ international dollars per LYS (starting at age 30 years in India and at age 25 years in Uganda). ${ }^{23}$

Source guidelines and discussion. In limitedresource settings, which often correspond to rural areas in middle-income countries, most of the recommendations are based on the $\mathrm{WHO}$ guideline. The triage of positive screening results will depend on resources and the sample available from the screening. If there is sufficient sample from the primary test and genotyping is available or if genotyping is concurrent, that should be used, as recommended by the Huh et $\mathrm{al}^{6}$ guideline. If not and if cytology meets $Q A$ metrics, ${ }^{5}$ that may be used. If cytology does not meet the $Q A$ metrics, then VAT should be used, as recommended by $\mathrm{WHO}^{28}$ If cytology results are positive, then women may receive quality-assured colposcopy, if available; otherwise, see and treat on the basis of the triage results. Although it was not within the scope of this guideline to develop de novo or formally review others' recommendations on QA for colposcopy, groups that have addressed this include the National Health Service ${ }^{49}$ and the Society of Canadian Colposcopists. ${ }^{50}$ In addition, the 2011 International Federation for Cervical Pathology and Colposcopy Nomenclature is used worldwide. ${ }^{51}$ 
If a woman has a history of abnormalities (eg, repetitively HPV-positive results) and recalling women for follow-up after abnormal results is a challenge, the woman might have an elevated risk for $\geqslant$ CIN2, and it might be cost-effective to offer treatment in limited or basic settings. (However, in enhanced and maximal settings, when recall is more feasible, further tests should be performed before treatment.)

The recommendation to follow-up other results if HPV genotyping is not available is a modification of $\mathrm{CCO}$ and $\mathrm{WHO}$ recommendations. The management of precursor lesions is based on the ASCCP $^{26}$ and WHO guidelines ${ }^{29}$; the latter supports performing LEEP. On the basis of each authority that provides screening CEA, women older than age 49 years with no previous screening may be offered screening, after the priority age group (30 to 49 years) is covered.

\section{Basic-Resource Setting}

If HPV DNA testing for cervical cancer screening is notavailable, then VIA should be offered with the goal of developing health systems and moving to population-based screening with HPV testing at the earliest opportunity. Screening should be offered to women age 30 to 49 years at least once per lifetime but not more than three times per lifetime (Type: evidence based; Evidence quality: intermediate; Strength of recommendation: strong). If the results of available HPV testing are positive, clinicians should then perform VAT followed by treatment with cryotherapy and/or LEEP, depending on the size and location of the lesion (Type: formal consensus based; Evidence quality: low; Strength of recommendation: moderate). If primary screening is VIA and results are positive, then treatment should be offered with cryotherapy and/or LEEP, depending on the size and location of the lesion (Type: evidence based; Evidence quality: intermediate ${ }^{52}$; Strength of recommendation: moderate).

After women receive treatment of precursor lesions, then follow up with the available test at 12 months. If the result is negative, then women should return to routine screening (Type: formal consensus based; Evidence quality: intermediate; Strength of recommendation: moderate).

CEAs. In addition to the study by Campos et $\mathrm{al}^{23}$ discussed in limited-setting recommendations, the study by Shi et $\mathrm{al}^{20}$ (found in ASCO literature search for CEAs) was a CEA that involved several substudies that compared HPV versus VIA versus $\mathrm{VIA}$ /visual inspection with Lugol's iodine once or twice per lifetime or at routine intervals for primary testing in rural China. The outcomes included cost-effectiveness, incidence, mortality, and optimal age ranges. The investigators found that the lowest cost-effectiveness ratio (CER) for screening (compared with no intervention) was associated with VIA once per lifetime at age 35 years, and the second lowest was with VIA twice per lifetime (at age 35 to 45 years). The average lifetime reduction in cancer mortality was $8 \%$ for once per lifetime for VIA and $12 \%$ for HPV; twice per lifetime reductions were $16 \%$ and $24 \%$, respectively. "Depending on the test technology used, and assuming a participation rate of approximately $70 \%$, we found that once-lifetime screening at age 35 years would reduce age-standardised cervical cancer mortality in the population by $8-12 \%$ over the long term, with a CER of \$557-959 per LYS. Regular screening at a feasible age-standardised participation rate of $62 \%$ in women aged $30-59$ years would reduce cervical cancer mortality by $19-54 \%$, with a CER of \$665-2,269 per LYS."20(p14) (The World Bank currently categorizes China as an upper-middle-income economy. ${ }^{53}$ )

Source guidelines and discussion. These recommendations are based on the WHO guideline. In basic settings, where there is no mass screening and no culture of screening, VIA may be used, with the goal of moving to population-based screening with HPV testing at the earliest opportunity. There have been mixed results regarding VIA as primary screening. A cluster RCT on VIA involving 151,538 women in India was published after the WHO guidelines. ${ }^{54}$ Outcomes including cervical cancer mortality and incidence for 75,630 women receiving four rounds of VIA plus cancer education were compared with those of 76,178 women receiving cancer education alone. The authors have published 12 years of follow-up. Age-adjusted rates (AARs) for incidence of cervical cancer were 29 (95\% Cl, 24.5 to 33.4) for VIA plus education compared with $29.4(95 \% \mathrm{Cl}, 27.2$ to 31.7) for education alone (incident rate ratio, 0.8-1.2; $P=.79$ ). AARs for cervical cancer mortality were 14.4 (95\% $\mathrm{Cl}, 12.7$ to 16.2$)$ for VIA plus education compared with 19.8 (95\% Cl, 17.8 to 21.8) for education alone, with an incident rate ratio of $0.69(95 \% \mathrm{Cl}$, 0.54 to $0.88 ; P=.003)$. All-cause mortality AARs were $1,340.5$ (95\% CI, 1,321.2 to 1,359.6) for VIA plus education compared with 1,391.3 (95\% Cl, $1,372.1$ to $1,410.4)$ for education alone, and the mortality rate ratio was $0.93(95 \% \mathrm{Cl}, 0.79$ to 1.1 ; $P=.41$ ). (All figures were for 100,000 person-years of observation. $)^{54}$ An earlier four-arm cluster RCT conducted in India compared HPV testing, 
cytology, VIA, and standard care; it was published with 8 years of follow-up. ${ }^{55}$ In that study, the statistically significant outcomes were in the HPV testing arm, but not in the VIA arm. The hazard ratio for mortality was $0.52(95 \% \mathrm{Cl}, 0.33$ to 0.83$)$ with HPV versus control. The hazard ratios for the incidence of stage II or higher cervical cancer were 0.47 (95\% Cl, 32 to 0.69) for HPV versus control and 1.04 (95\% Cl, 0.72 to 1.49$)$ for $\mathrm{VIA}$ versus control.

Screening with VIA helps build infrastructure and brings women into medical care and screening (eg, in Bangladesh and Tamil Nadu, India). ${ }^{56,57}$ If screening is not started, the infrastructure will not develop for HPV testing. This is recommended while recognizing that follow-up opportunities may be limited. Regions should build toward having systems in place to diagnose and treat women with positive results and invasive cancer. For public health entities that initiate VIA for primary screening, it is crucial to invest significant effort to use validated training and validation procedures. These entities must have a plan for quality control of trained VIA evaluators' performance.

After the establishment of such patterns, public health systems can introduce HPV testing. As these systems develop infrastructure for population-based screening, parallel development of systems for diagnosis and treatment of invasive cancer needs to occur. Concurrently with the development of screening programs, programs should develop the capacity to assess women with symptoms, including women outside of the target age range. In addition, the introduction of VIA screening may lead to identification of symptoms and women with symptoms seeking care. There may be high levels of screen-detected cancers on the first round of screening (many presumably in symptomatic women). Downstaging can be valuable too if treatment is available. The recommendations for age range, screening interval, triage, and special populations in the basic setting are modifications of the $\mathrm{WHO}$ recommendations. ${ }^{28}$ Follow-up of abnormal results and treatment of women with $\geqslant$ CIN2 follow the WHO recommendations on this condition. ${ }^{29}$

\section{Recommendations for Special Populations}

Recommendation SP1a: Women who are HIV positive. Women who are HIV positive should begin screening with HPV testing, every 2 to 3 years, as soon as they receive an HIV diagnosis. The recommended frequency depends on the resource level; in general, it should be twice as many times in a lifetime as in the general population (Type: formal consensus based;
Evidence quality: low; Strength of recommendation: weak).

The recommended frequencies, according to resource setting, are as follows:

- Maximal: Women should be screened for HPV approximately every 2 to 3 years.

- Enhanced: Women should be screened for HPV at intervals of 2 to 3 years, then, if negative, every 5 years (approximately eight screenings per lifetime).

- Limited: Women should be screened for HPV at intervals of every 2 to 3 years and twice as many times in a lifetime as in the general population (approximately four to six screenings per lifetime).

- Basic: If HPV testing is available, women with HIV should be screened for HPV as early as possible starting at age 25 , every 3 years if the test results are negative initially; approximately twice per lifetime. If HPV testing is not available, use VIA at the same intervals (Type: evidence-based; Evidence quality: low; Strength of recommendation: weak).

The management of abnormal results of screening for women with HIV and positive results of triage is the same as in the general population (Type: formal consensus based; Evidence quality: low; Strength of recommendation: moderate).

Recommendation SP1b: Women who are immunosuppressed-all settings. Women who are immunosuppressed for any reason other than HIV should be offered the same screening as women who are HIV positive (Type: formal consensus based; Evidence quality: insufficient; Strength of recommendation: weak).

Discussion of SP1a and SP1b. There is insufficient evidence regarding screening women with HIV; only the WHO guideline made specific recommendations regarding these women. There are no data to inform screening for women who are immunosuppressed for other reasons. In general, these recommendations agree with the $\mathrm{WHO}$ guidelines, with the grateful acknowledgment of the panel. ${ }^{52}$ In addition, Forhan et al ${ }^{58}$ performed a systematic review on seeand-treat strategies for women with HIV in LMICs and found a lack of long-term outcome data (including morbidity and mortality and some HIV-specific outcomes). All the studies found in the systematic review by Forhan et $a^{58}$ were observational.

Further, Vanni et al ${ }^{59}$ used a model-based approach to compare 27 strategies of primary HPV 
testing or cytology with triage of cytology, HPV, or colposcopy, and each of these combinations at 6 months, 1 year, or 2 years, for women with HIV in Brazil, which is characterized as a middle-income country. The authors found that once-yearly HPV testing with cytology triage would be the most costeffective strategy for women with HIV in Brazil with CER results of US $\$ 4,911$ per LYS, with the threshold of Brazil's per capita gross domestic product of US\$8,625 per LYS. ${ }^{59}$ (The World Bank currently categorizes Brazil as an upper-middle-income economy. ${ }^{53}$ )

Recommendation SP2a: Women who are pregnantall settings. Pregnant women should not receive screening.

Recommendation SP2b: Women who are postpartum-all settings. Women who are postpartum should be screened with VIA 6 weeks after delivery in basic settings. In other settings, HPV testing is recommended 6 months after delivery, unless there is uncertainty about completion of follow-up, in which case screening at 6 weeks after delivery is advised (Type for both: formal consensus based; Evidence quality: insufficient; Strength of recommendation: weak).

Discussion of SP2a and SP2b. There is no evidence available to support evidence-based recommendations for women who are pregnant or postpartum; therefore, the recommendations are based on formal consensus. There is some indication that as a result of immune changes during pregnancy, some pregnant women may have increased HPV, which can subside after pregnancy. Performing HPV testing during this time of elevation may then produce inaccurate results. The test specificity increases with time. However, in some settings, loss to follow-up may be a concern, and because women may already be seeing clinicians for a postpartum and/or new baby visit at 6 weeks, the recommendation presents an opportunity to screen when the likelihood of a 6-month visit is low. Providers can discuss the potential risks, including opportunity costs, and benefits of screening with pregnant women to help reach individual decisions.

Recommendation SP3: Women who have had hysterectomies (with no history of $\geq$ CIN2). In all settings, screening may be discontinued in women who have received a total hysterectomy for benign causes with no history of cervical dysplasia or HPV. Women who have received a subtotal hysterectomy (with an intact cervix) should continue to receive routine screening (Type: evidence-based; Evidence quality: high; Strength of recommendation: strong).

Discussion of SP3. The recommendation regarding women who have had hysterectomies was adapted from the 2011 CCO interim recommendations and the 2012 ACS/ASCCP/ASCP guidelines ${ }^{24,27}$ that state that no screening is necessary for women who have undergone hysterectomy with cervix removal and have had no history of $\geqslant$ CIN2 within the past 20 years. The ACS/ASCCP/ASCP recommendation on screening for vaginal cancer was based on observational data.

\section{SPECIAL COMMENTARY}

What Is the Role of Self-Collection (Only for HPV Molecular Testing)?

For improving coverage of screening, there is evidence emerging or under way on selfcollection (also known as self-sampling). Selfcollected (self-sampled) specimens may be used, with a validated collection device, transport conditions, and assay, as an alternative to providercollected specimens for HPV testing. Triage and follow-up must be performed according to the setting and resources available. An ASCO literature search found three systematic reviews and/or meta-analyses on self-collection. A meta-analysis by Arbyn et ${ }^{6}{ }^{60}$ found that " $[t]$ he pooled sensitivity of HPV testing on self-samples was lower than HPV testing on a clinician-taken sample (ratio 0.88 [95\% Cl 0.85 to 0.91] for CIN2 or worse and 0.89 [0.83 to 0.96] for CIN3 or worse). In addition, specificity was lower in self-samples versus clinician-taken samples (ratio 0.96 [0.95 to 0.97] for CIN2 or worse and 0.96 [0.93 to 0.99] for CIN3 or worse)."60(p127) There is a significant difference in the sensitivity of self-sampling versus cervical sampling when a signal amplification test is used, but that difference is minimal or null when a polymerase chain reaction-based test is used. A systematic review and meta-analysis by Racey et al $^{61}$ found that relative compliance was higher with home-based self-collection HPV DNA testing kits than with standard clinic-based cytology. An earlier systematic review by Stewart et al ${ }^{62}$ found high acceptability by women performing self-collection.

The self-collection protocol, which includes the specimen collection (ie, device), handling (ie, transport buffer and storage conditions), and HPV test, needs to be validated in limited and basic settings if not previously validated. For example, a temperature higher than what is recommended or a different transport medium may affect the test performance. 
As more evidence on self-collection is published, the Expert Panel will consider whether to make a formal recommendation.

What Screening Is Recommended for Women Who Have Received HPV Vaccination?

Public health providers should consider changes in cervical cancer screening in the HPV vaccination era in the absence of the two most carcinogenic HPV genotypes. As a consequence of the absence of HPV 16/18, positive screening tests will be less predictive of CIN3 and cervical cancer ( $\geqslant$ CIN3) because the point prevalence of $\geqslant$ CIN3 is expected to be reduced by $\geqslant 50 \%$, whereas the test positivity will be reduced by $\leqslant 30 \%$. 33,63,64 Moreover, HPV 16- and HPV 18-related cervical cancers occur at an earlier age than those related to other HPV genotypes ${ }^{65}$; therefore, the risk of cancer is also lowered. Less predictive screening means a poorer benefit-to-harm ratio. Although more data are needed, under the assumption that women were vaccinated before becoming sexually active, in the enhanced and maximal settings, women may receive routine screening with HPV testing at ages 30, 45, and 60 years. However, age and frequency cannot be fully addressed until there are more data.

Screening can be changed in several ways to help restore good benefit-to-harm ratios in bivalent or quadrivalent HPV-vaccinated populations. First, screening can be started at an older age than is currently implemented because the population risk of cervical cancer will be lower in HPVvaccinated (HPV 16 and HPV 18 negative) populations and cervical cancer caused by other HPV genotypes happens at a median age approximately 5 years older than does cervical cancer caused by HPV 16 and HPV 18. For example, many screening programs screen unvaccinated women under the age of 25 years, despite the lack of evidence of benefit in this age group, ${ }^{66}$ and vaccinated women in this age group would be even less likely to benefit given their lower cancer risk. Second, using the principle of equal management for equal risk, ${ }^{67}$ longer intervals between screens and/or follow-up in management could be considered. This would allow more benign infections and related abnormalities to clear without detection and intervention while shifting the focus to persisting HPV infections that carry a significant risk of progression. ${ }^{68,69}$ Finally, new, more specific biomarkers could be used to triage screen-positive women to help differentiate between benign hrHPV infections or related cytologic abnormalities and clinically important hrHPV infections that have caused, or will cause, $\geqslant \mathrm{CIN3}$. Although much more data are needed before new approaches can be implemented into routine screening practices, the most promising of these biomarkers include p16/Ki-67 immunocytochemistry, ${ }^{70}$ E6 oncoprotein detection, ${ }^{71}$ and HPV viral genome methylation. ${ }^{72,73}$ (See New Screening Technologies for background and discussion on biomarkers.)

Although it will be at least a decade before we will consider the predicted impact of the newest HPV vaccines, in HPV-naïve populations vaccinated with the nonavalent HPV vaccine, the question will be whether to screen at all. Most $\geqslant$ CIN3 will be prevented, especially if there is cross-protection against hrHPV not targeted by nonavalent HPV vaccine. The few remaining CIN3 diagnoses caused by borderline hrHPV or low-risk HPV genotypes may rarely, if ever, become invasive cancer. These HPV genotypes can still cause significant numbers of minor cytologic $^{74,75}$ and histologic ${ }^{76}$ abnormalities that have little clinical importance but would be picked up by screening. Thus, the harms to the women and costs would be disproportionately high compared with the benefits to women. Speculatively, a single screening of mid-adult-aged women approximately 35 or 40 years of age may be valuable if it leads to the detection of early-stage cervical cancer caused by hrHPV types not covered by the nonavalent HPV vaccine or caused by borderline hrHPV, and perhaps other female reproductive tract cancers, ${ }^{77}$ if the lead-time detection of the latter provides significant health benefit (eg, reduced mortality).

\section{New Screening Technologies}

Several new technologies are being investigated for all resource setting levels. They need to be tested and approved before use in any setting. These include a number of potentially promising new biomarkers that might achieve better performance as a triage for women with hrHPV-positive results than cytology and/or HPV genotyping. The most advanced of these next-generation biomarkers with respect to validation and readiness for introduction into routine practice is $\mathrm{p} 16^{\text {INK4a }}$ immunocytochemistry (p16 ICC). In a number of studies, p16 ICC has demonstrated high sensitivity and specificity that is similar to or better than cytology testing for $\geqslant$ CIN2 and $\geqslant$ CIN3 among women with hrHPV-positive results. ${ }^{70,78,79}$ In addition, Ki-67, a cell proliferation marker, has been included with p16 ICC (p16/Ki-67 ICC) as a dual stain to create a morphology-independent test. ${ }^{70}$

There is also a manual, lateral flow test for the detection of E6 protein that was developed for lower resource settings. The research use-only 
version of the test targeted HPV 16, HPV 18, and HPV 45 E6 protein, whereas the current commercialized version targets HPV 16 and HPV 18. HPV E6 protein detection has been shown to be more specific than DNA detection for CIN3 and cervical cancer, even when accounting for restriction to the detection of the highest risk HPV genotypes. ${ }^{71,80,81}$ Additional study is needed to confirm this test's performance.

There are a considerable number of additional biomarkers that are being developed. These include, but are not limited to, viral ${ }^{72,73,82,83}$ and host ${ }^{82,84-87}$ methylation, 3q amplification, ${ }^{88-93}$ and viral integration. ${ }^{94,95}$ All of these new biomarkers will need further study and validation before use in any clinical setting, regardless of resource level.

\section{COST AND POLICY IMPLICATIONS}

The secondary prevention of cervical cancer is a cost-effective strategy to reduce the incidence and mortality of cervical cancer. CEAs discussed in this guideline support the introduction of HPV DNA tests in maximal-, enhanced-, and limitedresource settings and the introduction of VIA in basic-resource settings. However, there are specific implementation issues regarding providing screening and treatment in limited and basic settings in primary care, outside of research studies.

The age group of 30 to 49 years (target age range recommended in limited- and basic-resources settings) represents approximately $20 \%$ to $25 \%$ of the entire population of women in a given country. LMICs typically have only basic health systems, lack resources and facilities, and have limited or no capacity to manage cancers. These formidable barriers to starting a screening program for this target group can lead to inertia. One strategy to overcome these barriers is to consider further restriction of the target age for screening. Targeting screening to women in their 30 s (eg, 30 to 39,30 to 34 , or 35 to 39 years) reduces the number of women needing screening, thereby reducing burden on the health care system and costs, and decreases the number of screendetected cancers, which typically peak in women in their 40s and 50s. Even targeting a single-year age group, for example, 30 or 31 years, would enable the development of programs to start and would help prevent cancer. When more resources and capacities become available, the program can be expanded for catch-up screening in older populations.

Additional strategies to further implementation of mass screening include buy-in from policymakers, which affects the provision of resources, including physical infrastructure, prioritizing cancer prevention, sponsorship of screening, and quality control. It is important to address this, at a minimum, by assessing the needs and preferences, follow-up systems, monitoring, evaluation, and partnering with institutions, regions, and countries with treatment facilities. A publication entitled "Infrastructure Requirements for Human Papillomavirus Vaccination and Cervical Cancer Screening in Sub-Saharan Africa" describes specific infrastructure elements needed for screening and cryotherapy programs and can help program managers plan for obtaining these elements. ${ }^{10}$

\section{GUIDELINE IMPLEMENTATION}

ASCO guidelines are developed for implementation across health settings. Barriers to implementation include the need to increase awareness of the guideline recommendations among front-line practitioners and women in general populations and also to provide adequate services in the face of limited resources. The guideline Bottom Line Box was designed to facilitate implementation of recommendations. This guideline will be distributed widely, including through many forms of ASCO communications and the ASCO Web site.

\section{LIMITATIONS OF RESEARCH}

There were limitations in the evidence regarding the best ages for starting and exiting from screening, screening women with HIV and other types of immunosuppression, comparative risks and benefits of treatment, and follow-up of women with precursor lesions. Future research is suggested in these areas.

\section{FUTURE DIRECTIONS}

In addition to addressing research limitations, future research is needed in other areas (eg, self-collection, biomarkers, needs and preferences of women, low-cost technology, and impact of vaccination on screening). Addressing policy/health system barriers may include the following:

- Education of medical and public health communities to change practices and incorporate new technologies

- Participation and sponsorship from policymakers

- Partnerships with institutions, regions, or countries with treatment facilities

- Coordinated volume purchasing and procurement of HPV testing 
- Improvement of health information systems to have better follow-up and treatment of women with positive screening results

- Quality control

- Monitoring and evaluation

\section{ADDITIONAL RESOURCES}

Additional information including a Data Supplement with additional tables, a Methodology Supplement with information about evidence quality and strength of recommendations, slide sets and clinical tools, and resources can be found at www.asco.org/rs-cervical-cancer-secondaryprev-guideline and www.asco.org/guidelineswiki. Patient information is available there and at www. cancer.net. Visit www.asco.org/guidelineswiki to provide comments on the guideline or to submit new evidence.

ASCO believes that cancer and cancer prevention clinical trials are vital to inform medical decisions and improve cancer care and that all patients should have the opportunity to participate.

DOI: https://doi.org/10.1200/JG0.2016.006577

Published online on jgo.org on October 12, 2016.

\section{AUTHOR CONTRIBUTIONS}

Administrative support: Sarah Temin

Manuscript writing: All authors

Final approval of manuscript: All authors

\section{AUTHORS' DISCLOSURES OF POTENTIAL CONFLICTS OF INTEREST}

The following represents disclosure information provided by authors of this manuscript. All relationships are considered compensated. Relationships are self-held unless noted. I = Immediate Family Member, Inst = My Institution. Relationships may not relate to the subject matter of this manuscript. For more information about ASCO's conflict of interest policy, please refer to www.asco.org/rwc or ascopubs.org/jco/site/ifc

Jose Jeronimo

No relationship to disclose

\section{Philip E. Castle}

Honoraria: Roche, Cepheid

Consulting or Advisory Role: Cepheid, GE Healthcare, Guided Therapeutics, Merck, Genticel, Teva, Inovio Pharmaceuticals

\section{Sarah Temin}

No relationship to disclose

\section{Lynette Denny}

Honoraria: GlaxoSmithKline, Merck

Speakers' Bureau: GlaxoSmithKline, Merck

Research Funding: GlaxoSmithKline

Travel, Accommodations, Expenses: Merck

Vandana Gupta

No relationship to disclose

Jane J. Kim

No relationship to disclose
Silvana Luciani

No relationship to disclose

Daniel Murokora

No relationship to disclose

Twalib Ngoma

No relationship to disclose

Youlin Qiao

Consulting or Advisory Role: MSD

Research Funding: GE Healthcare

Travel, Accommodations, Expenses: MSD

Michael Quinn

Consulting or Advisory Role: Tesaro, AstraZeneca

Travel, Accommodations, Expenses: Roche, Tesaro,

AstraZeneca

Rengaswamy Sankaranarayanan

No relationship to disclose

Peter Sasieni

Honoraria: Hologic

Expert Testimony: Teva, Mylan, Sandoz, Dr Reddys Laboratory

Kathleen M. Schmeler

Research Funding: Becton Dickinson

Patents, Royalties, Other Intellectual Property: UpToDate

Surendra S. Shastri

No relationship to disclose

\section{ACKNOWLEDGMENT}

The Expert Panel thanks Clinical Practice Guideline Committee reviewers Alexi A. Wright and Jene Rene V.

Clemenceau, the Clinical Practice Guidelines Committee, and Cosette Wheeler for their thoughtful reviews of and insightful comments on this guideline document and Shannon McKernin for her assistance.

\section{Affiliations}

Jose Jeronimo, PATH, Seattle, WA; Philip E. Castle, Global Coalition Against Cervical Cancer, Albert Einstein College of Medicine, Arlington; Sarah Temin, American Society of Clinical Oncology, Alexandria, VA; Lynette Denny, University of Cape Town, Cape Town, South Africa; Vandana Gupta, V Care; Surendra S. Shastri, Tata Memorial Center, Mumbai, India; Jane J. Kim, Harvard T.H. Chan School of Public Health, Boston, MA; Silvana Luciani, PanAmerican Health Organization, Washington, DC; Daniel Murokora, Uganda Women's Health Initiative, Kampala, Uganda; Twalib Ngoma, International Network for Cancer Treatment and Research, Dar Es Salaam, Tanzania; Youlin Qiao, Chinese Academy of Medical Sciences and Peking Union Medical College, 
Beijing, China; Michael Quinn, University of Melbourne, Melbourne, Victoria, Australia; Rengaswamy Sankaranarayanan, International Agency for Research on Cancer, Lyon, France; Peter Sasieni, Queen Mary, University of London, London, United Kingdom; and Kathleen M. Schmeler, The University of Texas MD Anderson Cancer Center, Houston, TX.

Editor's note: This American Society of Clinical Oncology Clinical Practice Guideline provides recommendations with review and analyses of the relevant literature for each recommendation. Additional information, which includes a Data Supplement, Methodology Supplement, slide sets, clinical tools and resources, and links to patient information at cancer. net, is available at: www.asco.org/rs-cervical-cancer-secondary-prev-guideline and www.asco.org/guidelineswiki.

\section{REFERENCES}

1. International Agency for Research on Cancer: GLOBOCAN 2012 Cervical Cancer: Estimated incidence, mortality and prevalence worldwide in 2012. http://globocan.iarc.fr/old/FactSheets/cancers/cervix-new.asp

2. Chuang LT, Temin S, Camacho R, et al: Management and care of women with invasive cervical cancer: American Society of Clinical Oncology resource-stratified clinical practice guideline. J Global Oncol 2:311-340, 2016

3. Sankaranarayanan R, Budukh AM, Rajkumar R: Effective screening programmes for cervical cancer in low- and middle-income developing countries. Bull World Health Organ 79:954-962, 2001

4. World Health Organization: Comprehensive Cervical Cancer Control: A Guide to Essential Practice (ed 2). Geneva, Switzerland, World Health Organization, 2014

5. von Karsa L, Arbyn M, De Vuyst H, et al: European guidelines for quality assurance in cervical cancer screening. Summary of the supplements on HPV screening and vaccination. Papillomavirus Res 1:22-31, 2015

6. Huh WK, Ault KA, Chelmow D, et al: Use of primary high-risk human papillomavirus testing for cervical cancer screening: Interim clinical guidance. Obstet Gynecol 125:330-337, 2015

7. Adesina A, Chumba D, Nelson AM, et al: Improvement of pathology in sub-Saharan Africa. Lancet Oncol 14:e152e157, 2013

8. Sayed S, Lukande R, Fleming KA: Providing pathology support in low-income countries. J Global Oncol 1:3-6, 2015

9. Olmsted SS, Moore M, Meili RC, et al: Strengthening laboratory systems in resource-limited settings. Am J Clin Pathol 134:374-380, 2010

10. Sankaranarayanan R, Anorlu R, Sangwa-Lugoma G, et al: Infrastructure requirements for human papillomavirus vaccination and cervical cancer screening in sub-Saharan Africa. Vaccine 31:F47-F52, 2013 (suppl 5)

11. Garland SM, Hernandez-Avila M, Wheeler CM, et al: Quadrivalent vaccine against human papillomavirus to prevent anogenital diseases. N Engl J Med 356:1928-1943, 2007

12. Hildesheim A, Herrero R, Wacholder S, et al: Effect of human papillomavirus 16/18 L1 viruslike particle vaccine among young women with preexisting infection: A randomized trial. JAMA 298:743-753, 2007

13. National Cancer Institute: Cervical Cancer Screening-Health Professional Version (PDQ®). Bethesda, MD, National Cancer Institute, 2016

14. Darragh TM, Colgan TJ, Thomas Cox J, et al: The Lower Anogenital Squamous Terminology Standardization project for HPV-associated lesions: Background and consensus recommendations from the College of American Pathologists and the American Society for Colposcopy and Cervical Pathology. Int J Gynecol Pathol 32:76-115, 2013

15. Moyer VA, US Preventative Services Task Force: Screening for cervical cancer: U.S. Preventive Services Task Force recommendation statement. Ann Intern Med 156:880-891, W312, 2012

16. Anderson BO, Shyyan R, Eniu A, et al: Breast cancer in limited-resource countries: An overview of the Breast Health Global Initiative 2005 guidelines. Breast J 12:S3-S15, 2006 (suppl 1)

17. Horton S, Gauvreau CL: Cancer in low- and middle-income countries: An economic overview, in Gelband H, Jha P, Sankaranarayanan R, et al (eds): Cancer Disease Control Priorities (ed 3). Washington, DC, International Bank for Reconstruction and Development/World Bank, 2015

18. ADAPTE Collaboration: The ADAPTE Process: Guideline Adaptation: A Resource Toolkit (version 2.0). http://www.g-in.net/document-store/working-groups-documents/adaptation/adapte-resource-toolkit-guideline-adaptation-2-0.pdf

19. Shiffman RN, Michel G, Rosenfeld RM, et al: Building better guidelines with BRIDGE-Wiz: Development and evaluation of a software assistant to promote clarity, transparency, and implementability. J Am Med Inform Assoc 19: 94-101, 2012

20. Shi JF, Canfell K, Lew JB, et al: Evaluation of primary HPV-DNA testing in relation to visual inspection methods for cervical cancer screening in rural China: An epidemiologic and cost-effectiveness modelling study. BMC Cancer 11 : 239, 2011

21. Beal CM, Salmerón J, Flores YN, et al: Cost analysis of different cervical cancer screening strategies in Mexico. Salud Publica Mex 56:429-501, 2014 
22. Vanni T, Legood R, Franco EL, et al: Economic evaluation of strategies for managing women with equivocal cytological results in Brazil. Int J Cancer 129:671-679, 2011

23. Campos NG, Tsu V, Jeronimo J, et al: When and how often to screen for cervical cancer in three low- and middleincome countries: A cost-effectiveness analysis. Papillomavirus Res 1:38-58, 2015

24. Saslow D, Solomon D, Lawson HW, et al: American Cancer Society, American Society for Colposcopy and Cervical Pathology, and American Society for Clinical Pathology screening guidelines for the prevention and early detection of cervical cancer. CA Cancer J Clin 62:147-172, 2012

25. Saslow D, Solomon D, Lawson HW, et al: American Cancer Society, American Society for Colposcopy and Cervical Pathology, and American Society for Clinical Pathology screening guidelines for the prevention and early detection of cervical cancer. J Low Genit Tract Dis 16:175-204, 2012

26. Massad LS, Einstein MH, Huh WK, et al: 2012 updated consensus guidelines for the management of abnormal cervical cancer screening tests and cancer precursors. Obstet Gynecol 121:829-846, 2013

27. Murphy J, Kennedy EB, Dunn S, et al: Cervical screening: A guideline for clinical practice in Ontario. J Obstet Gynaecol Can 34:453-458, 2012

28. World Health Organization: WHO Guidelines for Screening and Treatment of Precancerous Lesions for Cervical Cancer Prevention: WHO Guidelines Approved by the Guidelines Review Committee. Geneva, Switzerland, World Health Organization, 2013

29. World Health Organization: WHO Guidelines for Treatment of Cervical Intraepithelial Neoplasia 2-3 and Adenocarcinoma in Situ: Cryotherapy, Large Loop Excision of the Transformation Zone, and Cold Knife Conization. WHO Guidelines Approved by the Guidelines Review Committee. Geneva, Switzerland, World Health Organization, 2014

30. US Preventive Services Task Force: Final research plan for cervical cancer: Screening. http://www. uspreventiveservicestaskforce. org/Page/Document/final-research-plan/cervical-cancer-screening2

31. Brouwers MC, Kho ME, Browman GP, et al: AGREE II: Advancing guideline development, reporting and evaluation in health care. CMAJ 182:E839-E842, 2010

32. Jhpiego Corporation: Loop Electrosurgical Excision Procedure (LEEP) Services: A Reference Manual for Providers. Baltimore, MD, Jhpiego Corporation, 2015

33. Wright TC Jr, Stoler MH, Sharma A, et al: Evaluation of HPV-16 and HPV-18 genotyping for the triage of women with high-risk HPV+ cytology-negative results. Am J Clin Pathol 136:578-586, 2011

34. Dillner J, Rebolj M, Birembaut P, et al: Long term predictive values of cytology and human papillomavirus testing in cervical cancer screening: Joint European cohort study. BMJ 337:a1754, 2008

35. Ronco G, Dillner J, Elfström KM, et al: Efficacy of HPV-based screening for prevention of invasive cervical cancer: Follow-up of four European randomised controlled trials. Lancet 383:524-532, 2014

36. Rijkaart DC, Berkhof J, van Kemenade FJ, et al: HPV DNA testing in population-based cervical screening (VUSAScreen study): Results and implications. Br J Cancer 106:975-981, 2012

37. C Kitchener H, Canfell K, Gilham $\mathrm{C}$, et al: The clinical effectiveness and cost-effectiveness of primary human papillomavirus cervical screening in England: Extended follow-up of the ARTISTIC randomised trial cohort through three screening rounds. Health Technol Assess 18:1-196, 2014

38. Arbyn M, Ronco G, Anttila A, et al: Evidence regarding human papillomavirus testing in secondary prevention of cervical cancer. Vaccine 30:F88-F99, 2012 (suppl 5)

39. Harris LN, Ismaila N, McShane LM, et al: Use of biomarkers to guide decisions on adjuvant systemic therapy for women with early-stage invasive breast cancer: American Society of Clinical Oncology clinical practice guideline. J Clin Oncol 34:1134-1150, 2016

40. Meijer CJ, Berkhof J, Castle PE, et al: Guidelines for human papillomavirus DNA test requirements for primary cervical cancer screening in women 30 years and older. Int J Cancer 124:516-520, 2009

41. Stoler MH, Castle PE, Solomon D, et al: The expanded use of HPV testing in gynecologic practice per ASCCP-guided management requires the use of well-validated assays. Am J Clin Pathol 127:335-337, 2007

42. Martin-Hirsch PP, Paraskevaidis E, Bryant A, et al: Surgery for cervical intraepithelial neoplasia. Cochrane Database Syst Rev 12:CD001318, 2013

43. van der Heijden E, Lopes AD, Bryant A, et al: Follow-up strategies after treatment (large loop excision of the transformation zone (LLETZ)) for cervical intraepithelial neoplasia (CIN): Impact of human papillomavirus (HPV) test. Cochrane Database Syst Rev 1:CD010757, 2015

44. Castañón A, Landy R, Cuzick J, et al: Cervical screening at age 50-64 years and the risk of cervical cancer at age 65 years and older: Population-based case control study. PLoS Med 11:e1001585, 2014

45. The World Bank Group: GNI per capita, Atlas method (current US\$). http://data.worldbank.org/indicator/NY.GNP. PCAP.CD?page $=1$

46. Arbyn M, Anttila A, Jordan J, et al: European Guidelines for Quality Assurance in Cervical Cancer Screening: Second edition-Summary document. Ann Oncol 21:448-458, 2010 
47. Cuzick J, Powles T, Veronesi U, et al: Overview of the main outcomes in breast-cancer prevention trials. Lancet 361 : 296-300, 2003

48. Kotaniemi-Talonen L, Nieminen $\mathrm{P}$, Anttila A, et al: Routine cervical screening with primary HPV testing and cytology triage protocol in a randomised setting. Br J Cancer 93:862-867, 2005

49. Public Health England: NHS Cervical screening program: Colposcopy and programmer management, NHSCSP Publication number 20. https://www.gov.uk/government/uploads/system/uploads/attachment_data/file/508133/ NHSCSP_20_3rd_ed.pdf

50. Bentley J, Society of Canadian Colposcopists: Colposcopic management of abnormal cervical cytology and histology. J Obstet Gynaecol Can 34:1188-1206, 2012

51. International Federation for Cervical Pathology and Colposcopy: International Federation for Cervical Pathology and Colposcopy Nomenclature. http://www.ifcpc.org/images/docs/nomenclature7-11.pdf

52. World Health Organization: WHO Guidelines for Screening and Treatment of Precancerous Lesions for Cervical Cancer Prevention. WHO Guidelines Approved by the Guidelines Review Committee. Geneva, Switzerland, World Health Organization, 2013

53. The World Bank Group: Country and lending groups. http://data.worldbank.org/about/country-and-lending-groups

54. Shastri SS, Mittra I, Mishra GA, et al: Effect of VIA screening by primary health workers: Randomized controlled study in Mumbai, India. J Natl Cancer Inst 106:dju009, 2014

55. Sankaranarayanan R, Nene BM, Shastri SS, et al: HPV screening for cervical cancer in rural India. N Engl J Med 360: 1385-1394, 2009

56. Deodhar K, Sankaranarayanan R, Jayant K, et al: Accuracy of concurrent visual and cytology screening in detecting cervical cancer precursors in rural India. Int J Cancer 131:E954-E962, 2012

57. Nessa A, Hussain MA, Rahman JN, et al: Screening for cervical neoplasia in Bangladesh using visual inspection with acetic acid. Int J Gynaecol Obstet 111:115-118, 2010

58. Forhan SE, Godfrey CC, Watts DH, et al: A systematic review of the effects of visual inspection with acetic acid, cryotherapy, and loop electrosurgical excision procedures for cervical dysplasia in HIV-infected women in low- and middle-income countries. J Acquir Immune Defic Syndr 68:S350-S356, 2015 (suppl 3)

59. Vanni T, Luz PM, Grinsztejn B, et al: Cervical cancer screening among HIV-infected women: An economic evaluation in a middle-income country. Int J Cancer 131:E96-E104, 2012

60. Arbyn M, Verdoodt F, Snijders PJ, et al: Accuracy of human papillomavirus testing on self-collected versus cliniciancollected samples: A meta-analysis. Lancet Oncol 15:172-183, 2014

61. Racey CS, Withrow DR, Gesink D: Self-collected HPV testing improves participation in cervical cancer screening: A systematic review and meta-analysis. Can J Public Health 104:e159-e166, 2013

62. Stewart DE, Gagliardi A, Johnston M, et al: Self-collected samples for testing of oncogenic human papillomavirus: A systematic review. J Obstet Gynaecol Can 29:817-828, 2007

63. Stoler MH, Wright TC Jr, Cuzick J, et al: APTIMA HPV assay performance in women with atypical squamous cells of undetermined significance cytology results. Am J Obstet Gynecol 208:144.e1-8, 2013

64. Khan MJ, Castle PE, Lorincz AT, et al: The elevated 10-year risk of cervical precancer and cancer in women with human papillomavirus (HPV) type 16 or 18 and the possible utility of type-specific HPV testing in clinical practice. J Natl Cancer Inst 97:1072-1079, 2005

65. de Sanjose S, Wheeler CM, Quint WG, et al: Age-specific occurrence of HPV16- and HPV18-related cervical cancer. Cancer Epidemiol Biomarkers Prev 22:1313-1318, 2013

66. Sasieni P, Castanon A, Cuzick J: Effectiveness of cervical screening with age: Population based case-control study of prospectively recorded data. BMJ 339:b2968, 2009

67. Katki HA, Schiffman M, Castle PE, et al: Benchmarking CIN 3+ risk as the basis for incorporating HPV and Pap cotesting into cervical screening and management guidelines. J Low Genit Tract Dis 17:S28-S35, 2013 (suppl 1)

68. Castle PE, Rodríguez AC, Burk RD, et al: Short term persistence of human papillomavirus and risk of cervical precancer and cancer: Population based cohort study. BMJ 339:b2569, 2009

69. Kjær SK, Frederiksen K, Munk C, et al: Long-term absolute risk of cervical intraepithelial neoplasia grade 3 or worse following human papillomavirus infection: Role of persistence. J Natl Cancer Inst 102:1478-1488, 2010

70. Ikenberg H, Bergeron C, Schmidt D, et al: Screening for cervical cancer precursors with p16/Ki-67 dual-stained cytology: Results of the PALMS study. J Natl Cancer Inst 105:1550-1557, 2013

71. Qiao YL, Jeronimo J, Zhao FH, et al: Lower cost strategies for triage of human papillomavirus DNA-positive women. Int J Cancer 134:2891-2901, 2014

72. Mirabello L, Sun C, Ghosh A, et al: Methylation of human papillomavirus type 16 genome and risk of cervical precancer in a Costa Rican population. J Natl Cancer Inst 104:556-565, 2012 
73. Wentzensen N, Sun C, Ghosh A, et al: Methylation of HPV18, HPV31, and HPV45 genomes and cervical intraepithelial neoplasia grade 3. J Natl Cancer Inst 104:1738-1749, 2012

74. Kovacic MB, Castle PE, Herrero R, et al: Relationships of human papillomavirus type, qualitative viral load, and age with cytologic abnormality. Cancer Res 66:10112-10119, 2006

75. Wentzensen N, Nason M, Schiffman M, et al: No evidence for synergy between human papillomavirus genotypes for the risk of high-grade squamous intraepithelial lesions in a large population-based study. J Infect Dis 209:855-864, 2014

76. Joste NE, Ronnett BM, Hunt WC, et al: Human papillomavirus genotype-specific prevalence across the continuum of cervical neoplasia and cancer. Cancer Epidemiol Biomarkers Prev 24:230-240, 2015

77. Kinde I, Bettegowda C, Wang Y, et al: Evaluation of DNA from the Papanicolaou test to detect ovarian and endometrial cancers. Sci Transl Med 5:167ra4, 2013

78. Carozzi F, Confortini M, Dalla Palma P, et al: Use of p16-INK4A overexpression to increase the specificity of human papillomavirus testing: A nested substudy of the NTCC randomised controlled trial. Lancet Oncol 9:937-945, 2008

79. Carozzi F, Gillio-Tos A, Confortini M, et al: Risk of high-grade cervical intraepithelial neoplasia during follow-up in HPVpositive women according to baseline p16-INK4A results: A prospective analysis of a nested substudy of the NTCC randomised controlled trial. Lancet Oncol 14:168-176, 2013

80. Valdez M, Jeronimo J, Bansil P, et al: Effectiveness of novel, lower cost molecular human papillomavirus-based tests for cervical cancer screening in rural china. Int J Cancer 138:1453-1461, 2016

81. Zhao FH, Jeronimo J, Qiao YL, et al: An evaluation of novel, lower-cost molecular screening tests for human papillomavirus in rural China. Cancer Prev Res (Phila) 6:938-948, 2013

82. Brentnall AR, Vasiljević N, Scibior-Bentkowska D, et al: A DNA methylation classifier of cervical precancer based on human papillomavirus and human genes. Int J Cancer 135:1425-1432, 2014

83. Mirabello L, Schiffman M, Ghosh A, et al: Elevated methylation of HPV16 DNA is associated with the development of high grade cervical intraepithelial neoplasia. Int J Cancer 132:1412-1422, 2013

84. Vasiljević N, Scibior-Bentkowska D, Brentnall AR, et al: Credentialing of DNA methylation assays for human genes as diagnostic biomarkers of cervical intraepithelial neoplasia in high-risk HPV positive women. Gynecol Oncol 132:709714,2014

85. Wentzensen N, Sherman ME, Schiffman M, et al: Utility of methylation markers in cervical cancer early detection: Appraisal of the state-of-the-science. Gynecol Oncol 112:293-299, 2009

86. Hesselink AT, Heideman DA, Steenbergen RD, et al: Methylation marker analysis of self-sampled cervico-vaginal lavage specimens to triage high-risk HPV-positive women for colposcopy. Int J Cancer 135:880-886, 2014

87. Verhoef VM, Bosgraaf RP, van Kemenade FJ, et al: Triage by methylation-marker testing versus cytology in women who test HPV-positive on self-collected cervicovaginal specimens (PROHTECT-3): A randomised controlled noninferiority trial. Lancet Oncol 15:315-322, 2014

88. Andersson S, Wallin KL, Hellström AC, et al: Frequent gain of the human telomerase gene TERC at 3q26 in cervical adenocarcinomas. Br J Cancer 95:331-338, 2006

89. Heselmeyer K, Schröck E, du Manoir S, et al: Gain of chromosome 3q defines the transition from severe dysplasia to invasive carcinoma of the uterine cervix. Proc Natl Acad Sci USA 93:479-484, 1996

90. Hopman AH, Theelen W, Hommelberg PP, et al: Genomic integration of oncogenic HPV and gain of the human telomerase gene TERC at 3q26 are strongly associated events in the progression of uterine cervical dysplasia to invasive cancer. J Pathol 210:412-419, 2006

91. Rao PH, Arias-Pulido H, Lu XY, et al: Chromosomal amplifications, 3q gain and deletions of 2q33-q37 are the frequent genetic changes in cervical carcinoma. BMC Cancer 4:5, 2004

92. Thomas LK, Bermejo JL, Vinokurova S, et al: Chromosomal gains and losses in human papillomavirus-associated neoplasia of the lower genital tract: A systematic review and meta-analysis. Eur J Cancer 50:85-98, 2014

93. Andersson S, Sowjanya $P$, Wangsa $D$, et al: Detection of genomic amplification of the human telomerase gene TERC, a potential marker for triage of women with HPV-positive, abnormal Pap smears. Am J Pathol 175:1831-1847, 2009

94. Ojesina Al, Lichtenstein L, Freeman SS, et al: Landscape of genomic alterations in cervical carcinomas. Nature 506: 371-375, 2014

95. Vinokurova S, Wentzensen N, Kraus I, et al: Type-dependent integration frequency of human papillomavirus genomes in cervical lesions. Cancer Res 68:307-313, 2008 


\section{APPENDIX}

Table A1. Panel Members

Member

Affiliation

Expertise

\begin{tabular}{|c|c|c|}
\hline $\begin{array}{l}\text { Jose Jeronimo, MD, Co-Chair, Steering } \\
\text { Committee member }\end{array}$ & PATH, Seattle, WA & $\begin{array}{l}\text { Gynecologic Oncology, Cancer } \\
\text { Control }\end{array}$ \\
\hline $\begin{array}{l}\text { Surendra Shastri, MBBS, MD, DPh, DHA, } \\
\text { Co-Chair, Steering Committee member }\end{array}$ & Tata Memorial Centre, Mumbai, India & Preventive Oncology/Primary Care \\
\hline $\begin{array}{l}\text { Philip Castle, PhD, MPH, Steering } \\
\text { Committee member }\end{array}$ & $\begin{array}{l}\text { Albert Einstein College of Medicine; Global } \\
\text { Coalition against Cervical Cancer, } \\
\text { Arlington, VA }\end{array}$ & Epidemiology/Biophysics \\
\hline Lynette Denny, MD, PhD & $\begin{array}{l}\text { University of Cape Town, Capetown, South } \\
\text { Africa }\end{array}$ & Gynecologic Oncology \\
\hline Vandana Gupta & V Care, Mumbai, India & Patient Representative \\
\hline Jane J. Kim, PhD & $\begin{array}{l}\text { Harvard T.H. Chan School of Public } \\
\text { Health, Boston, MA }\end{array}$ & Health Economics \\
\hline Eduardo Lazcano, MD, PhD & $\begin{array}{l}\text { Research Center on Public Health } \\
\text { National Institute of Public Health, Mexico }\end{array}$ & Public Health \\
\hline Silvana Luciani, MHSc & $\begin{array}{l}\text { PanAmerican Health Organization, } \\
\text { Washington, DC }\end{array}$ & Cancer Control \\
\hline Daniel Murokora, MB, ChB & $\begin{array}{l}\text { Uganda Women's Health Initiative, } \\
\text { Kampala, Uganda }\end{array}$ & Medical Oncology \\
\hline Twalib Ngoma, MD & $\begin{array}{l}\text { International Network for Cancer Treatment } \\
\text { and Research, Dar Es Salaam, Tanzania }\end{array}$ & Radiotherapy and Nuclear Medicine \\
\hline Youlin Qiao, MD & $\begin{array}{l}\text { Chinese Academy of Medical Sciences and } \\
\text { Peking Union Medical College, Beijing, } \\
\text { China }\end{array}$ & Cancer Prevention and Control \\
\hline Michael Quinn, MD, MGO & $\begin{array}{l}\text { University of Melbourne, Melbourne, } \\
\text { Australia }\end{array}$ & Gynecologic Oncology \\
\hline $\begin{array}{l}\text { Rengaswamy } \\
\text { Sankaranarayanan, MD }\end{array}$ & $\begin{array}{l}\text { International Agency for the Research of } \\
\text { Cancer, Lyon, France }\end{array}$ & $\begin{array}{l}\text { Radiotherapy and Oncology; Cancer } \\
\text { Epidemiology and Control }\end{array}$ \\
\hline Peter Sasieni, PhD & $\begin{array}{l}\text { Queen Mary, University of London, Wolfson } \\
\text { Institute, London, United Kingdom }\end{array}$ & Biostatistics/Epidemiology \\
\hline Kathleen M. Schmeler, MD & $\begin{array}{l}\text { The University of Texas, MD Anderson } \\
\text { Cancer Center, Houston, TX }\end{array}$ & Gynecologic Oncology \\
\hline
\end{tabular}

Note. American Society of Clinical Oncology staff: Sarah Temin, MSPH. 
Table A2. Adapted Guidelines and Links

Guideline

\begin{tabular}{|c|c|c|}
\hline & & \\
\hline 1 & ACS/ASCCP/ASCP; Saslow et al., $2012^{24,25}$ & www.jlgtd.com \\
\hline 2 & ASCCP; Massad et al., $2013^{26}$ & www.asccp.org \\
\hline 3 & Cancer Care Ontario; Murphy et al., $2011^{27}$ & https://www.cancercare.on.ca/cms/one.aspx?pageld=10383 \\
\hline 5 & $\begin{array}{l}\text { SGO/ASCCP/ACOG/ACS/ASC/CAP/ASCP; } \\
\text { Huh et al., } 2015^{6}\end{array}$ & www.elsevier.com/locate/ygyno \\
\hline 7 & $\begin{array}{l}\text { WHO Guidelines for Treatment of Cervical } \\
\text { Intraepithelial Neoplasia } \\
\text { 2-3 and Adenocarcinoma In Situ, } 2014^{29}\end{array}$ & www.who.int/reproductivehealth/publications/cancers/treatment_CIN_2-3/en/index.htm \\
\hline
\end{tabular}

Abbreviations: ACOG, American College of Obstetricians and Gynecologists; ACS, American Cancer Society; ASC, American Society of Cytopathology; ASCCP, American Society for Colposcopy and Cervical Pathology; ASCP, American Society for Clinical Pathology; CAP, College of American Pathologists; SGO, Society of Gynecologic Oncology. 